\title{
CAN WE TALK? \\ Conversation, Collaboration, and Conflict for a Just Metro
}

\author{
Chris Benner and Manuel Pastor
}

In recent years, planners and community activists interested in broad issues of equity have shifted their attention to the metro level (Dreier, Swanstrom, and Mollenkopf 2013; Fox and Treuhaft 2005; Orfield and Luce Jr. 2010; Soja 2010). At least one of the initial impulses to move in this direction was the sense that the metropolitan region is where fundamental land-use patterns are set, where the driving clusters of the economy are forged, and where possibilities for redistribution and equity-oriented planning may be most fruitful. The argument for redistribution at a metro level has been bolstered by an emerging body of evidence that suggests that higher levels of inequality and social fragmentation diminish the potential for regional economic growth, thereby setting the stage for incorporating unusual allies into a conversation about metro futures (Benner and Pastor 2015a; Eberts, Erickcek, and Kleinhenz 2006). More broadly, the rubric of regional thinking provided a framework that at least rhetorically placed equity as a concern equal to that of the economy and the environment.

That new conversation was appealing in a world in which so many efforts to restructure opportunity had been stifled by right-wing politics — and the metro level was especially ripe because it is an arena in which the very fuzziness of jurisdictions and absence of governmental structures open up a new space for civic interconnection, knowledge creation, and governance. On the other hand, the very fuzziness of jurisdictional authority means that the metro region is also a level where tools for change can be in short supply. Transportation decisions may be at least somewhat regional, partly because of federal requirements, but the actual land-use decisions that locate housing close to or far from transit are done at the 
city level. Economic clusters are indeed metropolitan in character, but workforce development systems are frequently constrained to certain cities, and incentive packages used to lure business are also linked to jurisdictions. The overall pattern and affordability of housing is clearly regional but the very landscape is set by suburban jurisdictions using different density standards, while policies like inclusionary zoning are city level in their character.

The emergence of Donald Trump's presidency and the politics behind it has given us new appreciation for the importance and value of the regional equity frame. This is true for at least two key reasons. First is simply that under a Trump administration, the federal government has become a hostile force against equity in nearly all its forms, thus strengthening the need for work at a local, regional, and state scale in the years ahead. Second, on perhaps a more important level, many regions have been able to overcome the kinds of racial, ideological, and class divides that are so dominant in our national politics today. As such, they can offer lessons not just for equity planning, but for our national political environment as well.

So with this new pressing imperative, what's an equity planner to do? Is there really a new possibility for a "just metro," or is this just a new place or geographic level to talk about a "just city"? What are the metropolitan strategies and policies that can bring about change; what does it take in terms of organizing for power; and how does that intersect with conversation processes designed to build consensus? Is this really a call for more collaboration-and isn't conflict necessary to ensure that the issues of low-income and disenfranchised communities stay on the table? And what does all this imply for urban planners who may need to alter their practices to take a more metropolitan approach to equity planning and equity conversations?

These questions have preoccupied us for years - and not just as academics. We both started our journeys to metropolitan thinking from a very activist frame. One of us (Pastor) came of political age doing multiracial coalition-building both before and after the Los Angeles civil unrest while another (Benner) came to early professional practice as the research director for Working Partnerships USA, a labor-linked think-and-do tank in San Jose. This blend of activism and academics does not make us unusual among equity planners; our own observation is that equity planners tend not to be simply dispassionate technical experts who advocate for fairness - many, if not most, try to work directly with disadvantaged populations to help ensure their voices are heard in the planning process. What may set us off in this very collegial and forward-looking crowd is that we have been among those building the regional equity airplane even as we flew-that is, constructing the theory and empirics even as we embraced what looked like a promising venue for analysis and action. 
The regional promise was glimpsed mostly because of frustration and a sense that we needed to catch up to the times. In the Los Angeles case, it was clear that the old focus on the neighborhood just wasn't working - after all, community development had been detached from a booming downtown, and, in the infamous 1992 civil unrest, local neighbors had been willing to burn down their own environs when police brutality struck a match to the kindling of poverty. Seeing this, organizers and their allies needed to scale up to something bigger-and from the ashes of this unrest emerged groups like the Los Angeles Alliance for a New Economy, Strategic Concepts in Organizing and Policy Education (SCOPE), and many others who sought to devise new tools like community benefits agreements and also target inequities in regional transportation (Saito 2012). In San Jose, the very nature of the labor-community model undergirding Working Partnerships USA involved understanding the metropolitan economy to better wield power on behalf of working people; this was particularly called for because there was a need to respond to the "new regionalism" that uncritically celebrated Silicon Valley without understanding its underbelly of exclusion and rising inequality (Benner 2002, Dean and Reynolds 2009).

Thus, in this chapter, we will focus on issues of process and in particular the role of conversations about the metropolitan future. We specifically want to sketch further our emerging notion of "diverse and dynamic epistemic communities"knowledge communities in which data is generated, shared, and used to connect actors across sectors, races, ideologies, and interests in a region and forge a sense of common destiny. As we suggest below, there is not just one way to do this; we specifically suggest that the stewards of these processes can be planners, the business/civic elite, or social movement actors. We also stress that forging a metropolitan community or conversation is not without conflict; as Lester and Reckhow (2013) note, progress on equity generally emerges from more confrontational "skirmishes," particularly because justice advocates and disadvantaged communities frequently arrive with less power and so have less leverage in any such conversation. Whether through principled conflict or more collaborative processes, building diverse knowledge communities rooted in a commitment to reason and ongoing dialogue can play a critical role in creating more equitable regions.

We elaborate these ideas below as follows. We begin by discussing epistemic communities-how we discovered them, why we think they're important, and how we think they work at the metro level. We then discuss the ways in which such communities can facilitate shifts in the scale and scope of equity planning; who it is that can be the stewards of such conversations; and what skills and strategies equity planners might need in order to help build and strengthen such communities. We conclude by discussing how this all relates to improvements in planning practice and to the contemporary political scene. 


\section{Talking About the Region. . . .}

Researchers generally like to start with hypotheses that can be neatly tested in the field-or, better yet, on our computers in comfortable office settings. Our discovery of the importance of talk did not follow this path. Rather, we tried in a series of research articles and a book called Just Growth (2012) to first ask which metropolitan regions were achieving better performance on both job growth and income gaps and then to discover from exploratory data analysis and site visits what was driving the superior outcomes. We expected to find that structural factors mattered-and we did. There were beneficial and stabilizing effects, for example, from having a strong public sector and a minority middle class big enough to influence the economy and politics. But we also discovered in subsequent research-much like the study done by researchers at the International Monetary Fund (Berg, Ostry, and Zettelmeyer 2012) — that initial income inequality was the single largest and most statistically significant dragging factor on sustained economic growth (Benner and Pastor 2015a). It wasn't just this income difference that seemed to impact performance. Other measures that seemed to capture social distance (such as the degree of residential segregation; the diffusion of metropolitan power; and, as mentioned in our most recent book, even the extent of political spatial sorting) also played a role in limiting growth sustainability (Benner and Pastor 2015c). Something about growing apart seemed to get in the way of growing together.

And so off we went to look at those metros that were getting it right; some metros that were getting it wrong; and some metros that were either on the upswing or seemed to have lost a former advantage. ${ }^{1}$ The results of this latest research were published in a book called Equity, Growth, and Community: What the Nation Can Learn from America's Metropolitan Regions. ${ }^{2}$ In all, over the course of these two books, we have looked at seventeen metros, with many more coming into our view by virtue of other visits and projects. In each region, we interviewed a wide array of actors, with our questions to informants focused on their experiences in collaborating within the region, both within their broad societal sector (business, government, labor, community, philanthropy), and across sectors. We specifically probed for how people dealt with conflict by trying to understand major stakeholders in regional disputes, the values and priorities held by those different actors, how tensions between different constituencies was handled, and the extent to which diverse perspectives are incorporated (deliberately or informally) into formal governance structures and processes. We also reviewed a wide range of secondary material on each region, including academic work, reports, and media coverage. 
We did note that formal "ties that bind," particularly city-county consolidation and integrated metropolitan government structures, tended to cement a sense of common destiny that helped actors find common solutions. But we also discovered an amorphous set of regional cultures, social norms, and practices that seemed to set the stage for coming together-and, borrowing from some literature originally rooted in international policy conflict and cooperation (another sphere in which jurisdictional authority is not generally clear and so new implicit rules must be forged), we called these cultures, norms and practices "epistemic communities" (Haas 1992).

Formally, epistemic communities have been defined as like-minded networks of professionals whose authoritative claim to consensual knowledge provides them with a unique source of power in decision-making processes (Adler and Haas 1992, Haas 1992). As suggested above, though the concept has older roots in studies of scientific communities (Holzner 1968, Holzner and Marx 1979), it gained considerable attention in the early 1990s in the context of international policy development, particularly in situations with high degrees of uncertainty and unclear jurisdictions. The process of creating knowledge together, especially in a series of repeated interactions over extended periods of time, can help participants develop a common language and cognitive frames that allow them to communicate effectively. Epistemic communities build up trust between actors through the process of knowledge creation and sharing, leading to decisions that can produce better-if not optimal_outcomes. Think of it as a solution to collective action problems: when the invisible hand of the market won't do the trick, the very visible act of sharing knowledge can point the way.

In our research, we certainly didn't find people proudly declaring that they were part of an epistemic community-in fact, most observers think the term is clumsy till they try it on and find that our thicker description, offered below, is exactly what they're doing. But we did find a "Seattle Process" - a set of norms about talking out problems in the Seattle metro area that helped to produce a $\$ 15$ minimum wage, a firm commitment to affordable housing, and set of countylevel indicators to track progress on racial equity that is nearly unrivaled in the country. We did find an Envision Utah, a planning process that has settled tough planning conflicts in the Salt Lake City area, including steering transit availability to lower-income areas. We did find a transformed San Antonio-from a place riven by racial conflict over political representation and public infrastructure to an electorate that passed a sales tax on itself to support pre- $K$ for less-advantaged children-with some of the strongest advocacy coming from a chamber of commerce that once angered activists by trying to pitch San Antonio as a low-wage paradise. 
These did have the elements of epistemic communities, as written in the literature, but with several different characteristics that we think are critical. First, the traditional definition of epistemic communities involves a collection of experts - a group that is unlikely to be very diverse and indeed bonds over its professional similarities; in our case, the hallmark of a successful epistemic or knowledge community was its ability to be diverse and thus acknowledge different knowledge and ways of knowing. Second, the traditional definition of epistemic communities assumes that it is convened to solve a single problem and then disband when that is over; in our use of the concept, one key feature is that such a community is dynamic and can shift to other challenges as they arise. This is why we have labeled these collaborations "diverse and dynamic" epistemic communities.

Third, and perhaps most importantly, the traditional definition of epistemic communities seems to build on a rationalistic view of actors in which preferences are set and norms agreed to before coming together; the conversation is then about finding solutions based on a common commitment to data and the greater good. In our conception, the process itself is key because it actually shifts preferences, establishes norms, and creates identity (Akerlof and Kranton 2010). Indeed, it is crucial that members of such knowledge communities include not just the "usual suspects" of urban growth coalitions, but a broader constellation of community interests and perspectives.

While we try to concretize this a bit more below, the key point is that creating a diverse regional consciousness about the problems of poverty and its impacts on growth tends to help focus attention on these critical issues; interjurisdictional ties can help (because suburbs, for example, that can be annexed realize rather quickly that they cannot escape the drag on regional growth from high levels of poverty in the urban core); and all this can be pushed along by intentional leadership programs, collaborative planning processes, and other strategies for creating new conversations about metropolitan futures.

\section{A New Scale and Scope}

So what does all this mean for equity planners? Urban planning is typically understood as a combination of technical and political processes concerned with improving the welfare of people and their communities specifically by creating better places. The focus of urban planning, therefore, has historically been on the policies and practices that shape the use of land and the design of the urban environment, including air, water, and the infrastructure passing into and out of urban areas such as transportation, communications, and distribution networks. 
Of course, it's not just physical infrastructure; planners—and especially equity planners-also sometimes pay significant attention to the social interactions and decision-making processes that shape the physical characteristics of places, including helping design institutions and procedures that bring diverse constituencies together. Given the importance of local authorities in shaping places, the vast majority of city planning practice has been focused on cities and the neighborhoods within them.

As our urban areas have grown far beyond the boundaries of individual cities, however, the scale and scope of activities that are important for being effective have expanded, often to the metro or regional level. Unfortunately, this is a new sort of "final frontier" - one where there is limited governmental authority. In the absence of true regional governments, advocacy planners today have to be more comfortable navigating the complex terrain of regional governance. Achieving progress at the regional scale is not simply a matter of convincing a planning commission to adopt a particular plan, or getting a majority of elected officials in city council to pass a policy; more often it requires mobilizing a wide constituency, and convincing stakeholders to endorse change through a combination of methods, including research and data (to understand), advocacy (to convince), and political pressure (to force). It also means a greater appreciation for the interactions between local, regional, state, federal, and even global governance than was the case in the past and the ability to work across multiple types of organizations, including private sector, nonprofit, foundation, labor, and advocacy organizations. But rather than the interest-group-based, winner-take-all politics of conventional political structures, regional governance can resemble more the "deliberate democracy" of conversation and consensus building described by Iris Young (Young 2000).

What does this look like in practice? In Raleigh-Durham, the importance of a governance rather than government approach to regional equity is in part deeply rooted in the "Triple-Helix" model of public, private, and university collaboration that has become the backbone of the region's impressive growth. But it is also rooted in the work of the North Carolina Justice Center, a leading progressive research and advocacy organization that is widely recognized as the "go-to" organization for information and analysis on economic, social, and political justice in the region. In essence, it serves as a common information source for those concerned in the region about social and economic justice; perhaps surprisingly in most regions we've studied, there is no single common source for this kind of information, suggesting one role equity planners can help to play.

Meanwhile, in Sacramento, regional governance processes have revolved more around regional "blueprint planning" processes, which link land-use and transportation planning. These processes were not only important in getting cities, 
businesses, and community organizations throughout the region to work more closely together; they were also an important model for statewide climate change legislation designed to promote denser urban development. This state legislation, in turn, then provided a new tool that affordable housing and community development advocates throughout the state were able to use, along with environmental allies, to promote more equitable allocation of transportation and development dollars in regional planning. This link from region to state and back to region means that, to be effective, advocates and equity planners had to be able to navigate comfortably between hearings with elected officials in the state capital; coalition-building strategy sessions with local community leaders throughout the Central Valley; data-analysis and scenario planning assemblies with regional technical planners; and project development meetings with city council members and private sector developers. In this case as well, a regional data center with information on equity issues-UC Davis's Center for Regional Change-played a useful role in filling out the picture in a way that brought issues of inclusion into the mix.

It's not just the navigation between levels and jurisdictions that is important. Working at the expanded scale of a region also requires an expanded scope of topics with which equity planning has to engage. In the past, most equity planning work focused on the terrain of traditional planning departments—housing, land use, neighborhood development, community economic development, urban transit systems, and the like. Equity planners working at a regional scale today also work in these areas but are just as likely to also be engaged in struggles over workforce development initiatives, early childhood education, regional goods movement patterns, cluster-based economic development strategies, and even energy efficiency and climate mitigation policies. This requires the ability to incorporate insights from a wide range of areas of expertise and to navigate an even broader range of interests.

In Salt Lake City, for example, Envision Utah's recent long-range planning initiative-looking out to 2050-engaged in eleven issues of concern in the region: water, agriculture, energy, education, recreation, air quality, housing and cost of living, jobs and the economy, transportation and communities, public lands, and disaster resilience. As of March 2017, more than 54,000 residents had expressed their preference in these areas in an online survey (Envision Utah n.d.). In Oklahoma City, through multiple rounds of investments through the Metropolitan Area Projects initiative, specific projects have included many typical capital improvement and economic development projects (such as a baseball stadium, convention center renovations, improvements at the state fairgrounds, an urban canal entertainment district, a new public library, and a near-complete rebuilding of a music performance hall) and also major environmental projects (including 
transforming the North Canadian River into a series of river-lakes, with associated recreational facilities including a whitewater rafting and kayak center), major educational projects (more than $\$ 700$ million for technology and capital improvements in schools throughout the region), and the creation of four new senior health and wellness centers with associated active living programs. Kansas City's Mid-America Regional Council has programs on everything from early childhood education and Head Start to services for the aging, along with public health and health care, emergency services, and economic development programs that included for many years an international trade division.

What all these cases show is a willingness of metropolitan planners to go beyond the usual silos. Moving an equity agenda in that context requires also moving beyond the scale and scope of traditional planning efforts. Because this sort of bridging puts planners at the intersection of both jurisdictions and issues, detailed ongoing conversations among diverse constituencies are necessary to forge understanding and make progress. The development of data and a shared knowledge base can be helpful to go beyond "politics as usual."

\section{Regional Stewards and Social Movements}

The notion of a "regional steward" was developed with the creation of the Alliance for Regional Stewardship in May 2000. "Regional stewards," the founding document argued, "are integrators who cross boundaries of jurisdiction, sector, and discipline to address complex regional issues such as sprawl, equity, education, and economic development" (Henton and Alliance for Regional Stewardship 2000, 3). Despite its own largely elite-driven approach, the Alliance's commitment to making connections among an innovative economy, livable communities, social inclusion, and a collaborative style of governance is a useful framing, and this approach can be recognized in a much broader set of actors.

Indeed, our research suggests that, while processes creating diverse and dynamic epistemic communities might be linked to planning departments or agencies, they could just as easily happen in a range of structures and processes completely outside of formal urban planning. Importantly, such knowledge communities are not just collaborative forums; in fact, conflictual skirmishes can also both play an important role in building knowledge communities, as in San Antonio where the constant organizing of Communities Organized for Public Service (COPS) — an affiliate of the Industrial Areas Foundation organizing network-helped to change the political terrain and generate more civic concerns about disadvantaged communities. 
Indeed, there is also arguably a stronger role for community organizing and expanded social movements in regional equity planning than in equitable city efforts, given the often greater challenges in shifting entrenched power interests at a regional scale than within a single city. In our own case studies, regions that did not have experiences of strong social movements were able to achieve inclusive growth for some period of time but struggled in the face of more fundamental economic transformations. Grand Rapids and Charlotte, for example, are both places where a business elite with a strong sense of regional stewardship was successful in the 1980s and 1990s in leading broadly inclusive efforts to develop and restructure their regions. But as leadership aged and the economic and demographic changes in these regions became more diverse and complex, inequality increased with few organized voices to speak for marginalized populations.

Without a tradition of strong community organizing or influence of marginalized voices in regional decision making, inequality tends to increase or go unaddressed. Yet it is also important that the conflict inherent in political struggles contribute to a sense of common regional destiny, rather than reinforce antagonistic zero-sum frameworks - a shift that seems to require repeated interactions and extended communication over time. Overall, this suggests that an expanded notion of the stewards of regional equity and an expanded role for social movements are an important part of creating the kinds of diverse and dynamic epistemic communities that can lead to more equitable metros.

In some contexts, traditional planning agencies remain important regional stewards. In Sacramento, for example, cross-sector communication processes were driven primarily by the public sector through the efforts of the Sacramento Area Council of Governments (SACOG). Through a participatory process of developing long-range regional plans, SACOG helped a wide range of constituencies understand the importance of integrating land-use and transportation planning to ensure quality of life in the region. Initiated in the early 2000s, this "Blueprint Process" was prominent in the region's efforts to recover from economic shocks of the 1990s, and it also revealed some underlying yet commonly held values around resource conservation and sustainability, helping bridge gaps among otherwise uncommon allies.

In other contexts, traditional planning bodies are minor players, and the bridge building is led by other organizations. In Salt Lake City, for example, with its broadly held conservative and antigovernment sentiments, a very similar participatory process of long-range regional planning was led not by a regional government planning body but rather by the small nonprofit organization called Envision Utah. Despite different origins, the process of information sharing across diverse constituencies and the generation of broadly shared goals for regional development 
patterns informed by like values across diverse constituencies was quite similar to Sacramento. Here, the inclusion of diverse constituencies in regional planning processes was also facilitated by certain characteristics of the Mormon Church, entirely outside of formal planning processes. The lay clergy structure of the church, which brings large numbers of business and political leaders in their role as local bishops directly into the church's large social welfare programs, helps build systemic ties between elite-leadership and social work activities. The widespread international missionary experience of young Mormons has contributed to a remarkably open and welcoming tone around immigrant integration for such a conservative state.

In Oklahoma City, it was the chamber of commerce who played an important role in bringing diverse constituencies together. The Metropolitan Areas Projects (MAPS) initiatives brought together a range of different interests, including across partisan lines, as the Republican mayor and chamber of commerce were the leading advocates for the increased taxes required to pursue the MAPS project. The requirement that voters either approve all or none of the related projects associated with the tax increases required residents to understand a diversity of interests in the region. In Fresno, it was the philanthropic sector and community organizations which have been critically important in bringing together different constituencies in recent years; funding from the California Endowment in their Building Healthy Communities initiative was critical in supporting the participation of community organizations in a broad consultative process to create a new general plan in 2012 that was attempting to counter decades of largely unrestricted (and sometimes developer-corrupted) urban sprawl (Benner and Pastor 2015b). So, regional equity planning efforts are emerging from a wide variety of regional actors, which are only sometimes directly linked with formal planning processes.

The example of Fresno, however, highlights another key point from our research on the ability of regional planning processes to achieve regional equity: social movements are important for addressing inequities but they seem to work best in contexts where conflict doesn't lead to the demonization of opponents but rather helps build a sense of common destiny among constituencies with competing interests and values. Fresno is a place where social movements were quite strong in the 1970s, building on the significant United Farm Workers' history in the region. But in subsequent decades, the region has been unable to shift away from an economy rooted in low-wage labor, largely unrestricted urban sprawl, and lax environmental regulations that combined have produced a region with the second highest percentage of concentrated poverty and some of the worst air pollution in the country (Berube 2006). The absence of collaboration in the region, environmental justice and community activists told us, has led 
them to believe that their most promising path forward is through adversarial lawsuits rather than collaborative policy development. While there are hopeful signs_-including a new commitment to promoting downtown revitalization and a 2017 collaborative process to secure cap-and-trade revenues to invest in promotion of both downtown and surrounding low-income neighborhoods-as long as conflict in Fresno remains in a zero-sum and antagonistic framework, it is hard to see how the region will substantially shift from current development paths.

San Antonio provides a striking contrast. Here, in the 1970s and 1980s, the level of antagonism between activists and regional business leadership was also striking. As suggested above, COPS (an affiliate of the Saul Alinsky-founded Industrial Areas Foundation) was pursuing strategies to disrupt business to try to gain new investments in poor communities. The relationship between the organizers and business was so strained that Tom Frost, the head of a major local bank that was a COPS's target, was distributing copies of Alinsky's Rules for Radicals to his business colleagues in an effort to help them be better prepared to confront their adversaries. Yet this all too familiar antagonistic culture shifted over time to a more collaborative approach in which Tom Frost eventually became chair of a major COPS-initiated workforce development initiative called Project QUEST. Today, the chatter is all about how well different sectors collaborate (enough to get rewarded a Promise Neighborhood, a Choice Neighborhood, a Promise Zone, and a Sustainable Communities Initiative from the federal government). In 2012, a majority of residents voted to pass a sales tax increase that will steer additional resources to pre-K education for the least advantaged kids-with the support not only of a progressive mayor and community groups but also the chamber of commerce.

Why have key stakeholders in San Antonio been able to find ways to collaborate in the midst of conflict over competing interests and values? We believe organizing was a critical component of the story that helped to surface issues of equity and inclusion. But in contrast to Fresno, regional stakeholders were able to not let conflict get in the way of continued engagement. Over time- and facilitated through the deliberate efforts of a few key bridge-building individualsthis continued engagement evolved to a growing sense of common destiny and the broad culture and social norms of collaboration that characterize the region today. It was the repeated interactions, and a commitment on both sides to maintain a dialogue, that enabled San Antonio to move beyond unproductive conflict. 


\section{Skills and Strategies for Knowledge Building}

If we are right that diverse and dynamic epistemic communities can be valuable in underpinning processes of creating a just metro, planners may need to develop new skills or at least brush up and modify the skills they have. This calls for a dramatically expanded understanding of urban futures. Not only do planners have to understand the spatial and institutional aspects of land-use planning and infrastructure development, but as we've mentioned, they may also be called on to engage in a wide range of other issues, including workforce development, early childhood education, school integration, public health, energy policy, climate change, labor relations, policing and the criminal justice system, air and water quality, to name just a few. All of these emerged in our interviews as important dimensions of achieving sustainable equity processes in different regions.

But what seems to be valuable in many regions was not just the diversity of knowledge bases, but the collective nature of that knowledge development-and the planner's potential role in guiding that process. Perhaps the most obvious example of shared knowledge development in our case studies was in Salt Lake City, with the work of Envision Utah. Here, the explicit goal of their efforts was not to develop a detailed general plan for how the region should develop but rather to help identify the key values shared by a broad swath of Salt Lake City's population and translate that into more specific goals designed to guide regional development. The seven goals that emerged from this process-improving air quality, promoting housing options, creating transportation choices, encouraging water conservation, preserving critical lands, supporting efficient infrastructure, and exploring community development-are not particularly surprising or transformative in themselves.

What is critical is that these goals did not come from professional planners but instead emerged from a broad consultative, knowledge-generation process that included more than two thousand people in fifty public workshops and more than seventeen thousand responses to Internet and newspaper surveys. This process helped ensure that priorities for development in the region were rooted in the lived experiences and values of diverse communities and were broadly shared by leaders throughout the region. These public participation and distillation skills are critical to a new generation of planners and helped underpin future rounds of regional planning processes.

But perhaps as important as the knowledge-base planners' need to effectively engage in these conversations is the skill in framing issues and discussions. As we have learned from the work of George Lakoff and others, the way issues are framed makes a significant difference in how people understand the world and how they 
act (Bolman and Deal 2013, Lakoff 2004, Lakoff and Johnson 2008). We are most definitely not experts on cognitive linguistics, but we were struck in our case studies by the different ways people framed issues of conflict and collaboration in their work in the region. In more equitable regions, issues were framed around a respect for difference and a sense of a common future together; in more unequal regions, the frame was more about immediate interests and frustrations about lack of influence or impact.

Again, Salt Lake City provides an illustrative (and perhaps surprising) example of the more positive framing. In many parts of the United States, undocumented immigrants are viewed as an unwelcome alien invasion, and the strength of that aversion to immigrants was a key part of Trump's electoral victory. One might expect that to be the case in Utah, one of the country's politically reddest and, until recently, demographically whitest states. However, Utah has formally allowed undocumented immigrants to have legal driving privileges since 1999, and undocumented students have been able to pay in-state tuition at state universities since 2002. In the words of one Mexican immigrant, "I've lived in California. I've lived in Las Vegas. No place is like this. Here, they don't think just because we don't have papers we aren't human beings" (Riley 2006). Partly because of the Mormon faith, partly because of the stress on family, and partly because of an appreciation of markets and hard work, the rapidly growing immigrant population is seen as part of the overall fabric of the stateand that framing has had a real impact on policy.

This inclusionary framing stands in stark contrast to places like Fresno, where a number of respondents suggested that the problems are too large and the public too divided to actually work through solutions. Many in that region think that progress on equity can only be made by "standing up" to entrenched interests. That may well be, but "entrenched" also means "not going away." Eventually, conflict will need to shift to collaboration, as occurred in San Antonio, if there is to be significant impact on actual economic and social outcomes. While this might initially sound like a "collaborative leadership" approach (Chrislip and Larson 1994; Henton and Melville 1997; Innes and Rongerude 2005, 56; Kanter 1994), we prefer to think of it as "principled conflict." From this perspective, conflict includes a commitment to the idea that struggles should be waged with integrity and that it is possible to directly address real conflicts in goals, objectives, and values with opposing actors in a way that also recognizes the need to sustain longterm relationships, despite the parties' differences. This implies the need for a particular type of strategy - an approach that is able to both effectively represent particular values and interests and is also able to dialogue with opposing interests and "unusual allies" in the search for common ground and shared destiny. 
Finally, there is a very concrete skill and resource that planners can develop and contribute: data that focuses on equity. We are not naïve; we know that facts do not always win the day. But it's also the case that creating data sets that illustrate disparities and provide guidelines for remedies can be crucial, particularly when advocates are fighting to make sure their concerns are addressed as effectively as the concerns of those more focused on data-rich arenas like the economy and the environment. We noted in both the Raleigh and Sacramento cases how data provision from an equity perspective helped move along the dialogue; this was also the case in San Antonio where a data effort launched by then-Mayor Henry Cisneros helped keep disparities in the limelight. We have contributed to several efforts that have tried to create such tools: the Regional Opportunity Index (n.d.) that addressed integrated community opportunity throughout California; the National Equity Atlas (n.d.) which was developed in collaboration with PolicyLink; and an environmental justice screening method that was the precursor to CalEnviroScreen, a tool being using to target cap-and-trade proceeds for investment in less advantaged communities (Sadd et al. 2011). All have created platforms for discussion, policy, and organizing.

\section{Implications for Equity Planning}

In the face of rising inequality, growing social separation, entrenched political partisanship, and fragmented media, American policymaking often seems impossibly polarized. Yet even as the nation seems stuck in perpetual conflict in terms of facing our critical challenges, many metropolitan regions have found a more sustainable consensus on the direction their businesses, workers, and residents should work for, together. These better performing regions are often characterized by structural factors that facilitate coming together-such as shared jurisdictions, a stronger underlying economic base, or a sizeable minority middle class pushing for both growth and justice. But they are often also characterized by more subtle factors that seem to help explain their more successful outcomes: diverse constituencies weaving a sense of common regional destiny; ongoing dialogue and engagement despite differences that help to manage conflict in productive ways; and a commitment to data and reason rather than just opinions and ideology driving decision-making processes. Such efforts stand in stark contrast to less successful regions, where fragmented communities, zero-sum conflicts, and ideologically entrenched positions seem to undermine regions' ability to successfully address the challenges of our rapidly changing demographic and economic circumstances. 
We are not Pollyannaish about these efforts; they will not lift up issues of equity in the absence of strong social movements pushing progressive agendas. Even if such movements manage to get equity issues on the agenda, urban America is facing a strong headwind from the Trump presidency-successes at the regional level may be stymied by reactionary policies from DC. State governments can also be a barrier; already, some states such as Missouri, Alabama, Texas, and Arizona have pursued "preemption" strategies to prevent key cities anchoring metros to raise local minimum wages (Rivlin-Nadler 2016). Metro-level efforts are not a substitute for national- or state-level strategies - but they can be a base for making change, and they are a level on which deep social divisions can be at least potentially bridged.

Because of this, equity planners should expand their tool-kit and organizing skills. Certainly, planning must grow its scale and scope, paying greater attention to regional- rather than city-level processes; considering issues beyond the landuse and built environments issues that dominant planning; and addressing not just physical infrastructure but also the social infrastructure that can underpin regional knowledge sharing. This also requires expanding the sense of who is considered to be an important regional leader and working to expand these leaders' role in regional planning processes. And, of course, we need the data and ideas that can actually move the needle-so research and policy development remain key.

But we want to strongly suggest, as Yochai Benkler $(2011,117)$ argues in his path-breaking volume, The Penguin and the Leviathan, that

[t]alk is not cheap; through it we can come to define our preferences, goals, and desires in a situation; begin to build mutual empathy; negotiate what norms are appropriate and what course of action is fair; and begin to build trust and understand one another.

Conversation, in short, can help to change hearts and minds in ways that encourage collaboration rather than zero-sum competition. And this, in fact, may be one of the central things that planners can do: stop assuming that interests and preference are immutable and instead engage metropolitan and urban residents in ways that cause them to cease "othering" actors and communities and instead find uncommon common ground (Blackwell et al. 2010, Powell 2012). If they could help do that-and then bubble that up to a nation wracked by toxic inequality, social distance, and epistemic polarization - then that would be a healthy step forward for the nation as a whole.

\section{NOTES}

1. In our most recent effort, we selected the cases by examining the change in economic growth and social equity in four time periods: 1980s, 1990s, 2000s, and the entire 
thirty-year period (1980-2010). The indicators we used to measure economic growth were the change in employment and the change in earnings per job while the indicators we used to measure equity were the change in the percent living below poverty and the change in the ratio of household income for those at the eightieth percentile of the distribution relative to those at the twentieth percentile. To measure where the region stood at the end-point of our time frame, we used median household income, and to measure equity, we used the Gini coefficient.

2. This book, Equity, Growth, and Community: What the Nation Can Learn from America's Metro Areas (Berkeley: California University Press, 2015) is available for free download at the University of California Press open access imprint: http://www .luminosoa.org/site/books/10.1525/luminos.6/.

\section{REFERENCES}

Akerlof, G. A., and R. Kranton. 2010. Identity Economics: How Our Identities Shape Our Work, Wages, and Well-Being. Princeton: Princeton University Press.

Benkler, Y. 2011. The Penguin and the Leviathan: How Cooperation Triumphs over SelfInterest. New York: Crown Business.

Benner, C. 2002. Work in the New Economy: Flexible Labor Markets in Silicon Valley. Malden: Blackwell.

Benner, C., and M. Pastor. 2012. Just Growth: Inclusion and Prosperity in America's Metropolitan Regions. New York: Routledge.

— 2015a. "Brother, can you spare some time? Sustaining prosperity and social inclusion in America's metropolitan regions," Urban Studies 52 (7): 1339-56, https:// doi.org/10.1177/0042098014549127.

—. 2015b. "Collaboration, Conflict and Community-Building at the Regional Scale: Implications for Advocacy Planning," Journal of Planning Education and Research 35 (3): 307-22.

- 2015c. Equity, Growth, and Community: What the Nation Can Learn from America's Metro Areas. Berkeley: University of California Press.

Berg, A., J. D. Ostry, and J. Zettelmeyer. 2012. “What makes growth sustained?" Journal of Development Economics 98 (2): 149-66, https://doi.org/10.1016/j.jdevec0.2011.08.002.

Berube, A. 2006. Confronting Concentrated Poverty in Fresno. Washington, DC: Brookings Institution. http://www.brookings.edu/ /media/Files/rc/speeches/2006/0906metro politanpolicy_berube/20060906_fresno.pdf.

Blackwell, A. G., S. Kwoh, M. Pastor, and American Assembly. 2010. Uncommon Common Ground: Race and America's Future. New York: W.W. Norton.

Bolman, L. G., and T. E. Deal. 2013. Reframing Organizations: Artistry, Choice, and Leadership. 1st ed. San Francisco: Jossey-Bass.

Chrislip, D., and C. Larson. 1994. Collaborative Leadership. San Francisco: Jossey-Bass.

Dean, A. B., and D. B. Reynolds. 2009. A New New Deal: How Regional Activism Will Reshape the American Labor Movement. Ithaca: ILR Press.

Dreier, P., T. Swanstrom, and J. H. Mollenkopf. 2013. Place Matters: Metropolitics for the Twenty-First Century. 2nd ed.; rev. ed. Lawrence: University Press of Kansas.

Eberts, R., G. Erickcek, and J. Kleinhenz. 2006. Dashboard Indicators for the Northeast Ohio Economy: Prepared for the Fund for Our Economic Future. Cleveland: Federal Reserve Bank of Cleveland.

Envision Utah. n.d. Website. Accessed March 2015. http://envisionutah.net (now http:// www.envisionutah.org).

Fox, R., and S. Treuhaft. 2005. Shared Prosperity, Stronger Regions: An Agenda for Rebuilding America's Older Core Cities. Oakland: PolicyLink. 
Haas, P. M. 1992. "Introduction: Epistemic Communities and International Policy Coordination," International Organization 46 (1): 1-35, https://doi.org/10.1017 /S0020818300001442.

Henton, D. C., and Alliance for Regional Stewardship. 2000. Regional Stewardship: A Commitment to Place. Palo Alto: The Alliance for Regional Stewardship. http:// www.regionalstewardship.org/Documents/Monograph1.pdf.

Henton, D., and J. Melville. 1997. Grassroots Leaders for a New Economy: How Civic Entrepreneurs Are Building Prosperous Communities. San Francisco: Jossey-Bass.

Holzner, B. 1968. Reality construction in Society. Cambridge: Schenkman.

Holzner, B., and J. Marx. 1979. Knowledge Affiliation: The Knowledge System in Society. Boston: Allyn and Bacon.

Innes, J. E., and J. Rongerude. 2005. Collaborative Regional Initiatives: Civic Entrepreneurs Work to Fill the Governance Gap. San Francisco: The James Irvine Foundation. http://folio.iupui.edu/handle/10244/46.

Kanter, R. M. 1994. "Collaborative Advantage: The Art of Alliances," Harvard Business Review 72 (4): 96-108.

Lakoff, G. 2004. Don't Think of an Elephant! Know Your Values and Frame the Debate: The Essential Guide for Progressives. White River Junction, VT: Chelsea Green.

Lakoff, G., and M. Johnson. 2008. Metaphors We Live By. Chicago: University of Chicago Press.

Lester, T. W., and S. Reckhow. 2013. "Network governance and regional equity: Shared agendas or problematic partners?” Planning Theory 12 (2): 115-38. https://doi.org /10.1177/1473095212455189

National Equity Atlas. n.d. Website. http://nationalequityatlas.org.

Orfield, M., and T. F. Luce Jr. 2010. Region: Planning the Future of the Twin Cities. Minneapolis: University of Minnesota Press.

Powell, John A. 2012. Racing to Justice: Transforming Our Conceptions of Self and Other to Build an Inclusive Society. Bloomington: Indiana University Press.

Regional Opportunity Index. n.d. Website. University of California, Davis. http://interact .regionalchange.ucdavis.edu/roi/.

Riley, M. 2006. "Utah's embrace: no documents, no problem," Denver Post, April 1. Accessed June 26, 2014. http://www.denverpost.com/search/ci_3663998.

Rivlin-Nadler, M. 2016. "Preemption Bills: A New Conservative Tool to Block Minimum Wage Increases,” New Republic, February 29. Accessed April 3, 2017. https:// newrepublic.com/article/130783/preemption-bills-new-conservative-tool-block -minimum-wage-increases.

Sadd, J., M. Pastor, R. Morello-Frosch, J. Scoggins, and B. M. Jesdale. 2011. "Playing It Safe: Assessing Cumulative Impact and Social Vulnerability through an Environmental Justice Screening Method in the South Coast Air Basin, California," International Journal of Environmental Research and Public Health 8 (5), 1441-59, https://doi.org/10.3390/ijerph8051441.

Saito, L. T. 2012. "How Low-Income Residents Can Benefit from Urban Development: The LA Live Community Benefits Agreement," City \& Community 11 (2), 129-50, https://doi.org/10.1111/j.1540-6040.2012.01399.x.

Soja, E. W. 2010. Seeking Spatial Justice. Minneapolis: University of Minnesota Press.

Young, I. M. 2000. Inclusion and Democracy. New York: Oxford University Press. 